\title{
Simulation Study on the Static Stresses of an Diesel Engine Block Based on Different Experimental Physical Model Cases
}

\author{
Xiuwei Cheng ${ }^{a}$, Guoying Wang ${ }^{b}$, Changzhen Liu $^{c}$, Man Wang ${ }^{d}$, Hongli Wang ${ }^{e}$ \\ China North Engine Research Institute, Tianjin 300400, China \\ axiuweicheng2008@126.com, ’ g.y.wang@126.com, liu_changz@sina.com, \\ d18622907675@163.com, eemailwas00163@sina.com
}

\begin{abstract}
Keywords: Engine Block, Engine, Static Stress, Experimental Physical Model
Abstract. The 3D solid models of two different testing physical model case of a diesel engine block are established. Based on those two cases, a static analysis on the preload working conditions and explosion working conditions are conducted for the engine block structure. The results shows that the stresses of each measuring point of case 1 and case 2 are almost same at the preload working conditions. At the two different explosion working conditions, the trend distributions of measuring points are similar, the stresses of measuring points $1 \sim 4$ of case 1 are less than the case 2 , but the stresses of measuring points 5 8 of case 1 are greater than the case 2, this trend indicates the tensile stresses at the transition of bearing cap top is increasing obviously, there appears stress concentration at those areas.
\end{abstract}

\section{Introduction}

In the diesel engine experiment, the physical model includes all parts of engine, and analyses the loads effect of every cylinder. If the experiment is taken to the engine block, the physical model always only includes the parts of the cylinder, which is under the loads explosion, such as cylinder liner, cylinder gasket, cylinder head etc., the cylinder head only taken the effect of the explosion cylinder[1-3]. Therefore, the difference of the components of physical models is huge between whole engine experiment and engine block experiment. By the dynamics calculation, the loads of cylinders except for the explosion cylinder are little, the influence of the engine block can be neglected. Because the factor of structure restrictions and loads, at the experiment of engine block, there sets up the strain gauge on the bulkhead of engine block[4]. According to SAINT-VENANT'S principle, the influence of the stress state of the bulkhead is tiny by the loads of cylinder head. So the physical model of engine block experiment is made of the components that relate to the explosion cylinder, in order to reduce the experiment's cost.

The engine block of a diesel engine was studied by two different cases of the experiment physical model, analyzed the results of the simulation models, to decide the effective experiment physical model and get data to research the relation between the static stress of simulation model and the experimental physical model.

\section{Experimental Physical Models and Simulation Models}

\section{The Experimental Physical Models}

The engine block is the framework of diesel engine, it plays the role of sustaining and fixing of all components. The engine block is impacted the forces or stresses of cylinder heads, main crankshaft bearings and cylinder explosion pressures [5]. The establishment process of engine block physical model is combined of the structure model of engine block and other simplified components. There are normally two experimental physical models: one is the normal crankshaft, recorded as case 1, and another is nonstandard straight crankshaft, recorded as case 2. The two model cases is shown in Fig. 1. 


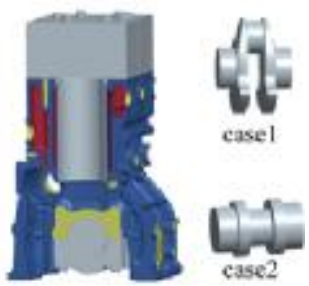

Fig. 1. Experimental physical model cases of Engine block

\section{The Simulation Models and Boundary Conditions}

The finite element models of engine block is shown in Fig. 2. The cell of engine and bearings caps adopt the two ranks correction tetrahedral mehses, other parts adopt hexahedron meshes, the materials of the physical models are shown in Table 1.

Table.1. Physical properties of model materials

\begin{tabular}{|c|c|c|c|}
\hline Sector & Material & \multirow{2}{*}{ Elastic modulus/GPa } & Poisson Ratio \\
\hline Cylinder head & HT250 & 115 & 0.26 \\
\hline Engine block & HT250 & 115 & 0.26 \\
\hline Bolt & High Strength Structure Steel & 210 & 0.3 \\
\hline Cylinder liner & Gary Cast Iron & 115 & 0.27 \\
\hline Cylinder gasket & 08F Steel & 210 & 0.3 \\
\hline Main bearing cap & DJS600 & 174 & 0.27 \\
\hline Crankshaft & 42CrMoA & 210 & 0.3 \\
\hline Nonstandard straight shaft & 42CrMoA & 210 & 0.3 \\
\hline
\end{tabular}

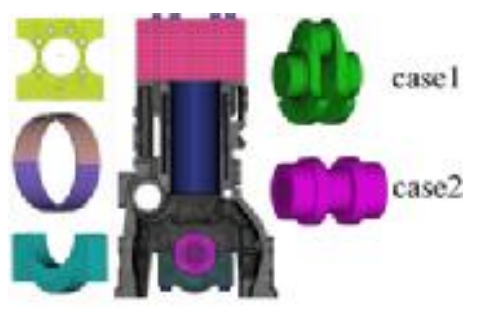

Fig. 2. Finite element model cases of engine block

The pre-tightness force of cylinder head bolts and main shaft bearing bolts are $55 \mathrm{kN}$, the explosion pressures are $17 \mathrm{MPa}$ and $29 \mathrm{MPa}$, the gap between the crankshaft and bearing bushes is $0.06 \mathrm{~mm}$, the tight fit of bearing bushes is $0.04 \mathrm{~mm}$.

\section{Results Analysis of Simulation Models}

The Mises Stress, Maximum Main Stress and Minimum Main Stress at preload working condition and the explosion pressure conditions (include $17 \mathrm{MPa}$ and $29 \mathrm{MPa}$ ) of case 1 are shown in the Fig. 3 $\sim$ Fig. 5. The Mises Stress, Maximum Main Stress and Minimum Main Stress at preload working condition and the explosion pressure conditions (include $17 \mathrm{MPa}$ and $29 \mathrm{MPa}$ ) of case 2 are shown in the Fig. $6 \sim$ Fig. 8 .

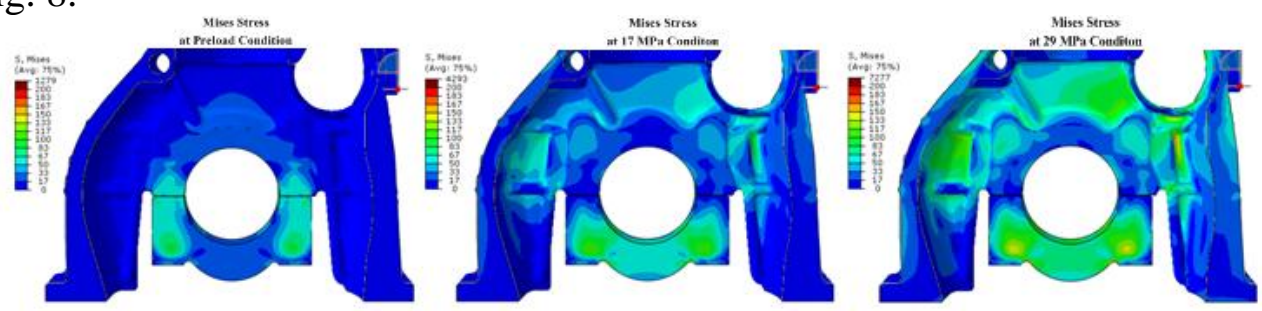

Fig. 3. Mises Stress at different working conditions of case1 

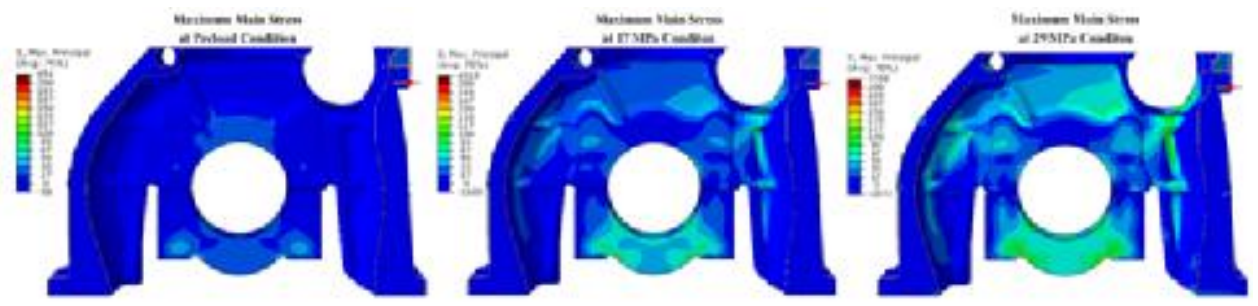

Fig. 4. Maximum Main Stress at different working conditions of case1
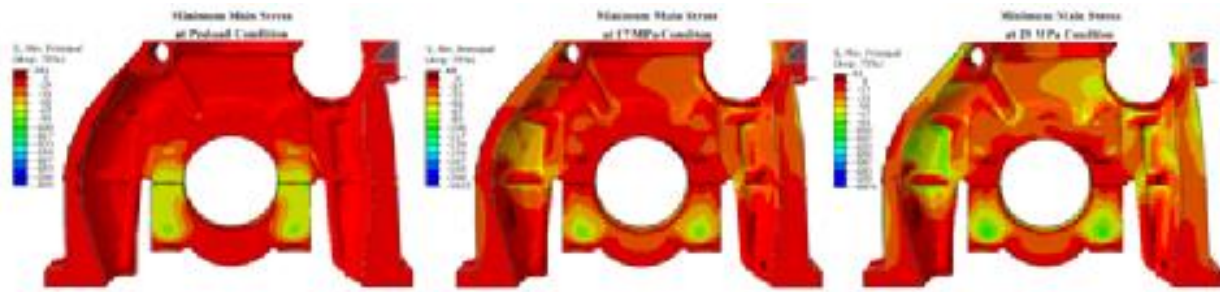

Fig. 5. Minimum Main Stress at different working conditions of case 1

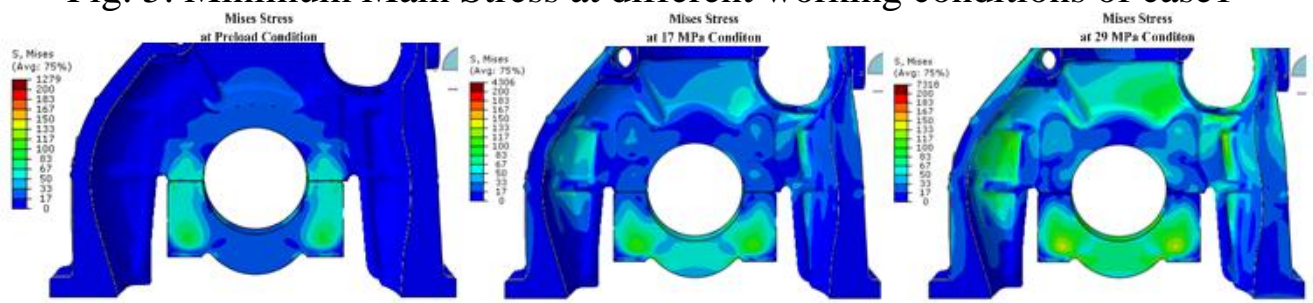

Fig. 6. Mises Stress at different working conditions of case2

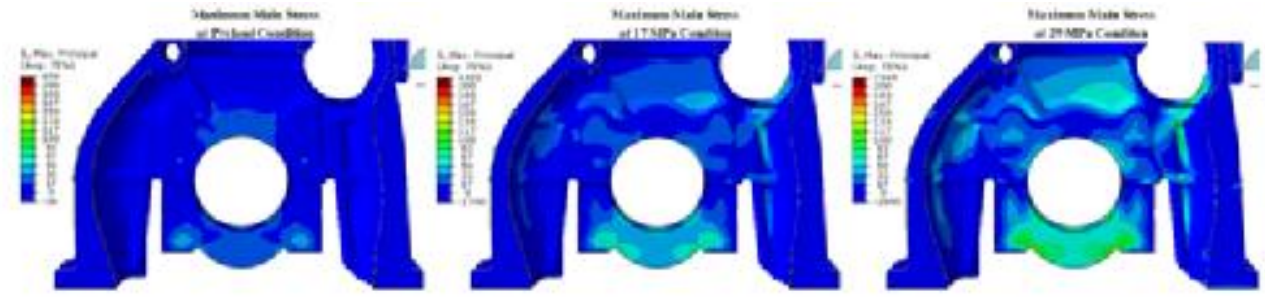

Fig. 7. Maximum Main Stress at different working conditions of case1

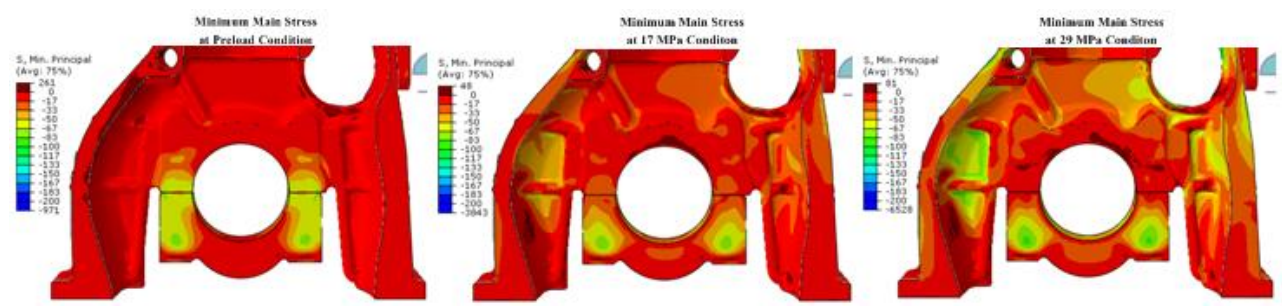

Fig. 8. Minimum Main Stress at different working conditions of case2

From the Mises stress maps, it can conclude that stress at the distinct around of main shaft bearing cap bolts is bigger than other area at preload condition, the maximum stress appear at the contact face between the head of main shaft bearing cap bolts with the main shaft bearing cap, it is caused by the static pre-tightness force of bolts. At explosion conditions, stresses at the distinct around of main shaft bearing cap bolts, the transition area around the head of shaft bearing cap and screw thread are bigger than other area, and the stresses increase with the explosion pressure, the stresses are caused by press stress of the contact face between engine block with main shaft bearing cap.

From the Maximum Main Stress and Minimum Main Stress maps, it can conclude that stresses at the compression distinct in head of main shaft bearing cap bolts and the contact face between engine block with main shaft bearing cap are bigger than other area at preload condition, the transition area around the head of shaft bearing cap appears tensile stress. At explosion conditions, the stresses at the compression distinct in head of main shaft bearing cap bolts and the contact face between engine block with main shaft bearing cap are decreased, the tensile stress at the transition area around the 
head of shaft bearing cap is sharply increased, there appears stress concentration at those areas, the stress is higher than other area of shaft bearing cap, It consistent with the fatigue test results of engine block, is shown in the Fig. 9.

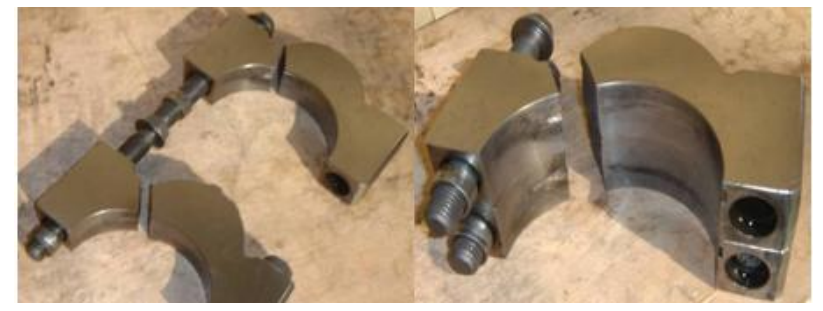

Fig. 9. Fatigue failure charts of shaft bearing cap

From the results of the engine block simulations, the different static stresses of 8 measuring points of the two experimental physical models cases are shown in Fig. 10.

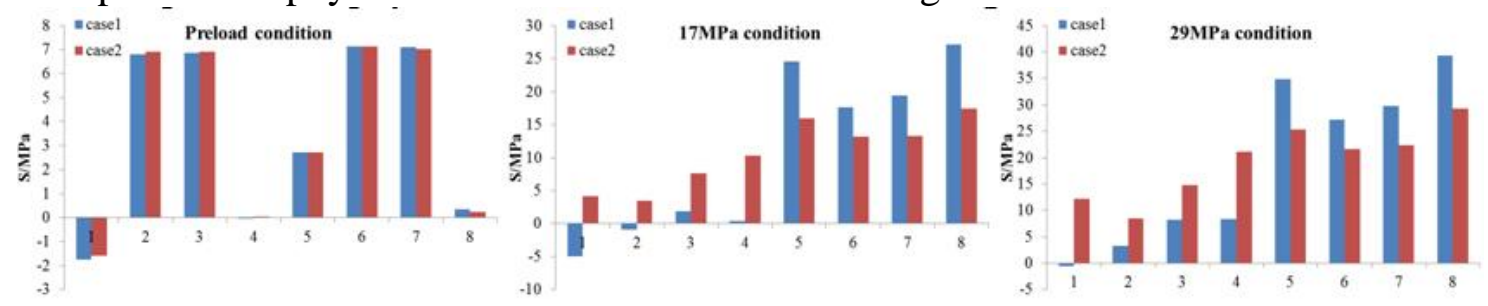

Fig. 10. Static stresses of different experimental physical models cases

\section{Conclusions}

Two different experimental physical models with a normal crankshaft and another nonstandard straight crankshaft are established, and the results of the finite element analysis of different models is shown that: the stresses of each measuring point of case 1 and case 2 are almost same at the preload working conditions. At the two different explosion working conditions, the trend distributions of measuring points are similar, the stresses of measuring points $1 \sim 4$ of case 1 are less than the case 2 , but the stresses of measuring points 5 8 of case 1 are greater than the case 2 . At explosion conditions, the stresses at the compression distinct in head of main shaft bearing cap bolts and the contact face between engine block with main shaft bearing cap are decreased, the tensile stress at the transition area around the head of shaft bearing cap is sharply increased, there appears stress concentration at those areas.

\section{References}

[1] Y.G. Sun, H.M. Du and X. Zhou: submitted to Journal of Chinese Internal Combustion Engine Engineering (2009)

[2] L. Yin, M.H. Li, L. Ni, et al: Advanced Materials Research (Trans Tech Publications, Switzerland 1987)

[3] M.H. Sadeghi, M. Zehsaz and M.M. Ettefagh: submitted to International Journal of Vehicle Systems Modeling and Testing (2011)

[4] Y.M. Hu, Z.X. Deng, Z.G. Zhu, et al: submitted to Journal of Chinese Internal Combustion Engine Engineering (2005)

[5] M. Birth, S. Papez: Proceedings - Society of Automotive Engineers (SAE, Warrendale, PA, USA 1982) 